\title{
Enseñar teología en universidades católicas colombianas: aciertos e interpelaciones*
}

\section{José Luis Meza-Rueda}

https://orcid.org/0ooo-0002-6520-2653 Pontificia Universidad Javeriana, Colombia

joseluismeza@javeriana.edu.co

\section{Arturo Herreño-Marín}

https://orcid.org/00oo-0003-2138-1618 Fundación Universitaria Católica Lumen Gentium, Colombia aherreno@unicatolica.edu.co

\section{Leonardo Rojas-Cadena}

https://orcid.org/00oo-0001-6426-031X Pontificia Universidad Javeriana,

Colombia

lrojas@javerianacali.edu.co

\section{José Orlando Reyes-Fonseca}

https://orcid.org/000o-0001-9249-2927 Pontificia Universidad Javeriana, Colombia

jose.reyes@javeriana.edu.co

\section{Adriano Padilla-Ramírez}

https://orcid.org/00oo-0002-5054-6736 Pontificia Universidad Javeriana de Cali, Colombia apadilla@javerianacali.edu.co

\section{Resumen}

Las prácticas de enseñanza en las asignaturas de indole teológica ofrecidas por universidades católicas a todos sus estudiantes en respuesta a su misionalidad y su deseo de formación integral son el tema del presente artículo, cuyo objetivo es caracterizar tales prácticas en relación con las concepciones de teología, intencionalidades formativas, contenidos, métodos, recursos y evaluación. El método de la investigación es el estudio de caso múltiple y se llevó a cabo en cuatro universidades de Colombia (dos en Bogotá y dos en Cali). En su propósito de identificar las construcciones meto-

* Artículo de investigación derivado de los resultados de la investigación Prácticas de enseñanza en la formación teológica en contexto universitario. Estudio de caso múltiple en universidades de fundación e inspiración católica de Bogotá y Cali, aprobada y financiada por la Pontificia Universidad Javeriana. Código: 008768. Fecha de inicio: 17-02-2019. Fecha de finalización: 16-08-2020.

Recepción: 22/04/2021 | Envío a pares: 06/07/2021 | Aceptación por pares: 21/08/2021 | Aprobación: 29/09/2021

Meza-Rueda, J. L., Reyes-Fonseca, J. O., Herreño-Marín, A., Padilla-Ramírez, A. y Rojas-Cadena, L. (2021). Enseñar teología en universidades católicas colombianas: aciertos e interpelaciones. Educación y Educadores, 24(3), e2432. DOI: https://doi.org/10.5294/ edu.2021.24.3.2 
ISSN 0123-1294 | e-ISSN 2027-5358 | Educ.Educ. Vol. 24. No.3 | Agosto-octubre de 2021 | e2432

Universidad de La Sabana | Facultad de Educación

dológicas y las acciones intencionadas que se implementan para que los estudiantes aprendan a pensar teológicamente la realidad, se encontró que: existen prejuicios por parte de los estudiantes que van desapareciendo a lo largo de la asignatura; los profesores no se inscriben en un único enfoque pedagógico y, en consecuencia, no se identifica una didáctica especifica; $y$, finalmente, aunque hay un aporte significativo en la formación humana de los estudiantes, lo propio de la teología queda diluido en asuntos religiosos, morales, sociales, políticos y ecológicos.

\section{Palabras clave (Fuente: tesauro de la Unesco)}

Educación cristiana; enseñanza de la teología; pedagogía universitaria; prácticas de enseñanza; universidades católicas; enseñanza superior; teología; universidad; humanidades. 


\title{
Teaching Theology in Colombian Catholic Universities: Successes and Interpellations*
}

\begin{abstract}
Teaching practices in theological courses offered by Catholic universities to all their students in response to their mission and comprehensive education are the subject of this article. In this sense, its objective is to characterize such practices concerning theology conceptions, formative intentions, contents, methods, resources, and assessment. The method used in our research is a multiple case study carried out with four universities in Colombia (two in Bogota and two in Cali). In identifying the methodological constructions and intentional actions implemented so that students learn to weigh reality theologically, we found that students have prejudices that are overcome throughout the course; professors do not restrict themselves to a single pedagogical approach and, consequently, specific didactics is not identified; and, finally, there is a significant contribution to the human education of students, but theology itself becomes blurred among religious, moral, social, political, and ecological issues.
\end{abstract}

\section{Keywords (Source: Unesco Thesaurus)}

Christian education; teaching of theology; university pedagogy; teaching practices; catholic universities; higher education; theology; uiversity; humanities.

Research article derived from the study "Prácticas de enseñanza en la formación teológica en contexto universitario. Estudio de caso múltiple en universidades de fundación e inspiración católica de Bogotá y Cali," approved and funded by the Pontificia Universidad Javeriana. Code: 008768. Start date: 02-17-2019. End date: o8-16-2020. 


\title{
Ensinar teologia em universidades católicas colombianas: acertos e interpelações*
}

\author{
Resumo
}

As práticas de ensino das disciplinas de indole teológica oferecidas por universidades católicas a todos os estudantes em resposta a sua missão e a seu desejo de formação integral são o tema deste artigo, cujo objetivo é caracterizar essas práticas com relação às concepções de teologia, às intencionalidades formativas, aos conteúdos, aos métodos, aos recursos e à avaliação. O método da pesquisa é o estudo de casos múltiplos e foi realizado em quatro universidades da Colômbia (duas em Bogotá e duas em Cali). Em seu propósito de identificar as construções metodológicas e as ações intencionadas que são implementadas para que os estudantes aprendam a pensar teologicamente na realidade, constatou-se que existem preconceitos por parte dos estudantes que vão desaparecendo ao longo do curso; que os professores não estão vinculados a uma única abordagem pedagógica e, em consequência, não é identificada uma didática especifica; finalmente, que, embora haja uma contribuição significativa na formação humana dos estudantes, o objetivo em si da teologia se dilui em assuntos religiosos, morais, políticos e ecológicos.

\section{Palavbras-chave (Fonte: tesauro da Unesco)}

Educação cristã; ensino da teologia; pedagogia universitária; práticas de ensino; universidades católicas; ensino superior; teologia; universidade; humanidades.

Artigo de pesquisa derivado dos resultados da pesquisa intitulada "Práticas de ensino na formação teológica em contexto universitário: estudo de casos múltiplos em universidades de fundação e inspiração católica de Bogotá e Cali", aprovada e financiada pela Pontificia Universidad Javeriana, Colômbia. Código: 008768. Início: 17 de fevereiro de 2019. Término: 16 de agosto de 2020 . 
Las universidades católicas' tienen como uno de sus propósitos la promoción del diálogo entre fe y saberes en el contexto académico y el cometido de la formación integral. Como respuesta, entre otras estrategias, ofrecen en su catálogo de asignaturas algunas que se fundan parcial o totalmente en la teología, en coherencia con sus apuestas misionales y sus proyectos educativos (Thivierge, 2012). No obstante, esto no resulta fácil, por la exacerbada "cientifización" del conocimiento, la formación utilitarista y los currículos profesionalizantes en los cuales parecen no tener cabida el humanismo ni las ciencias del espíritu (Torres, 1994a; 1994b; Peresson, 2004; Nussbaum, 2010; Cortina, 2013). Aun así, en las universidades católicas la formación teológica es reconocida por su aporte académico, moral (formación humana) y profesional (formación disciplinar), así como por su promoción de un compromiso sociocrítico. ${ }^{2}$

Animados por identificar cuáles son las caracteristicas de las prácticas de enseñanza en la formación teológica de algunas universidades de fundación e inspiración católica de Bogotá y Cali, nos dimos a la tarea de revisar aspectos referidos a: sus objetivos, intencionalidades, sentidos y significados; la promoción y apropiación de los valores del Evangelio; la coherencia entre el enfoque pedagógico y la didáctica; y los contenidos, perspectivas metodológicas y procesos evaluativos, todo con el

1 En adelante, la denominación universidad católica en este artículo ha de entenderse como aquella institución de educación superior inspirada por el Evangelio que responde a los lineamientos de la iglesia católica romana. En este sentido, tal tipo de universidad atiende a las constituciones apostólicas Ex Corde Ecclesiae de Juan Pablo II (1990) y Veritatis Gaudium de Francisco (2018), en las cuales se pide ofrecer cursos de teología a estudiantes que estén cursando otros programas.

2 El estado del arte reveló la existencia de un creciente interés por la relación pedagogía-teología, la didáctica de la teología y los alcances de la formación teológica. Al respecto ver (Arteaga, 2002; López, 2002; Mafla, 2004; Garcez, 2008; Saines, 2009; Silva, 2010; Walton, 2012; Andraos, 2012; Pontificia Universidad Javeriana, 2013; Bidlack et al., 2014; Harrison y Debergue, 2015; Togarasei, 2015; y Kenney, 2015).

3 Las universidades participantes en Bogotá: Pontificia Universidad Javeriana y Universidad de La Salle; y en Cali: Universidad Católica Lumen Gentium y Pontificia Universidad Javeriana. fin de caracterizar las prácticas de enseñanza en las propuestas de formación teológica ofrecidas a estudiantes pertenecientes a programas diferentes a la teología. Así las cosas, el presente artículo quiere dar cuenta de sus resultados.

En el primer apartado se presentan los conceptos de prácticas de enseñanza y enseñanza teológica; luego, el segundo apartado expone el caso múltiple como método usado en la investigación; y en la tercera parte, la más rica y extensa, se presentan los hallazgos más relevantes en torno a las prácticas de enseñanza en la formación teológica, acompañados de aciertos e interpelaciones que bien podrían ser acogidos reflexivamente por las universidades católicas y otras instituciones interesadas en el tema.

\section{Marco conceptual}

Dos conceptos están en la base de la investigación llevada a cabo: prácticas de enseñanza y enseñanza teológica.

\section{Prácticas de enseñanza}

Según Jaramillo (2005), enseñar (del sánscrito sek, seguir, y no, señal) es "hacer marcas", colocar signos que otros puedan seguir. Si articulamos los términos práctica y enseñanza, según Suriani (2003), las prácticas de enseñanza, en cuanto prácticas sociales, están históricamente determinadas, es decir, insertas en contextos particulares; al ser sociales, involucran sujetos que comparten múltiples representaciones (dentro del imaginario colectivo), que indican tradiciones, rutinas, modos de pensar y hacer propios de las prácticas. Por ser sociales, las prácticas de enseñanza se entienden como "formas específicas de prácticas educativas, pues se relacionan con lo cultural y con la producción y reconstrucción del conocimiento" (Jaramillo, 2005, p. 24).

Para Basabe y Cols (2008), las prácticas de enseñanza se constituyen en la acción de un docente que es a la vez un sujeto biográfico y un actor social, acción situada que transcurre en escenarios históricos, 
sociales, culturales e institucionales; y se inscriben en un tiempo o en muchos tiempos: los del docente, los del grupo de estudiantes y los de la institución. Las prácticas de enseñanza implican una particular organización de las actividades en las cuales sus actores intervienen en la realidad en el marco de sucesos en curso. Estas suponen por parte del docente la capacidad de atribuir sentido a su obrar y de llevar a cabo los procesos de reflexión en torno a su actuación.

Pero ¿qué caracteriza la acción del profesor? En primer lugar, la enseñanza está orientada hacia el logro de finalidades pedagógicas. La intencionalidad está a la base de todas las acciones del docentey se encuentra vinculada a la transmisión cultural de una serie de saberes relevantes, en el marco de un proyecto educativo. En segundo lugar, la enseñanza es una acción orientada hacia otros y realizada con otros a partir del diálogo, por tanto, descansa en un proceso de comunicación. La enseñanza es comunicación. En este sentido, Burbules (1999) afirma que ella se asume como una forma de diálogo que no se reduce a la utilización de un método didáctico. En tercer lugar, enseñar conlleva un papel mediador entre el estudiante y los saberes que va a adquirir en su proceso formativo. Las vinculaciones que establece el docente con los estudiantes quieren facilitar el logro de ciertos objetivos y el aprendizaje de ciertos contenidos. La tarea del profesor debe orientarse a impulsar de manera sistemática dicha apropiación, diseñando situaciones que permitan promover procesos de aprendizaje y construcción de significados por parte del estudiante. Y, finalmente, el proceso de enseñanza enfrenta al docente a un flujo constante de diversas situaciones, algunas de ellas inéditas, pero sobre todo complejas, que ocurren en lugares o escenarios fuera o dentro del aula. La enseñanza es una acción práctica -no se entienda como algo instrumental y operativo-, porque exige reflexión, deliberación y sabiduría experiencial (phronesis) de parte de quien enseña.

Además, las prácticas de enseñanza son expresión del acervo de conocimientos, teorías persona- les y creencias del docente, denominados por algunos teóricos como los implícitos sobre la enseñanza (Gajardo, 2008; Rodrigo, Rodríguez y Marrero, 2008; Woolfolk, Davis y Pape, 2006). A partir de estos, los profesores dan sentido e interpretan las acciones cotidianas del aula de clase. Los implícitos llevan a preguntarse cuáles son los procesos de pensamiento que se visualizan en las tareas de la enseñanza, qué caracteriza el conocimiento profesional que tiene el docente, de dónde provienen sus fuentes y qué relación se establece entre el conocimiento práctico y el conocimiento especializado. Lo que los profesores creen, piensan y conocen se constituye en una gran pista para entender lo que hacen en clase y las decisiones que toman con respecto a la enseñanza. Los implícitos son certezas que provienen de múltiples fuentes y son adquiridos a través del tiempo y de procesos en los cuales convergen factores de índole social, cultural y biográfica.

Por su parte, De Camilloni (2012) afirma que la enseñanza implica poner en práctica una gama de actividades que involucran ámbitos muy diversos, los cuales se llevan a cabo en momentos y escenarios diferentes. Enseñar no se puede reducir a los aspectos más visibles, pues enseñar es pensar, valorar, imaginar, es decir, construir muchas representaciones acerca de las actividades del aula, hablar acerca de ella y ser capaz de comunicar a otros las intenciones que se persiguen con el acto de enseñar.

Lo anterior permite ver que las prácticas de enseñanza no solo tienen una estrecha relación con los saberes pedagógicos (Cárdenas et al., 2012) sino también con las construcciones metodológicas (Edelstein, 2011). Más aún, prácticas, saberes y construcciones se vinculan con la didáctica. En términos generales, la didáctica tiene que ver con las maneras de promover el aprendizaje de un estudiante y las maneras de acceder a formas culturales que se encuentran contenidas en el currículo. En otras palabras, la didáctica conlleva las decisiones que un docente toma con respecto a los objetivos y propósitos de la enseñanza (dimensión teleológica) junto con 
los contenidos, formas de presentación y materiales a utilizar (dimensión metódica).

En síntesis, las prácticas de enseñanza no se reducen a secuencias didácticas (know-how). Aunque las asumen, se entienden como actividad social institucionalizada y contextualizada, acción e interacción dialogante de sujetos históricos (estudiantes y profesores) que poseen unas ideas e imaginarios, comunicación de un saber o conocimiento disciplinar, expresión y concretización de finalidades educativas, pedagógicas y didácticas encaminadas a la formación integral, y transformación social de la comunidad educativa participante.

\section{Enseñanza teológica}

El segundo concepto nuclear está referido a la enseñanza teológica en el escenario universitario católico (Sebá, 2000; Nicolás, 2008; Cordovilla, 2014; Aranda, 2015; O'Callaghan, 2015; Sánchez y Jiménez, 2015; Valdrini, 2015; Garanzin, 2016). No obstante, como ella puede ser problematizada en términos de sus condiciones y aceptación, es legítimo preguntarse por los elementos teóricos y prácticos identitarios de una propuesta académica cuya pretensión formativa se pregunte por el sentido histórico-salvífico del Evangelio, por las condiciones y posibilidades del ser humano para comprender el acontecimiento Cristo y por las consecuencias que tiene para su existencia personal y social el dejarse transformar por la acción del Espíritu (Meza, 1999). De aquí que la universidad católica pretenda:

... una educación teológica renovada, pertinente a las necesidades de las personas y del contexto, capaz de visualizar los signos de los tiempos, que anunciey denuncie, que se encarne en el corazón de los alumnos y les ayude a desarrollar sus talentos y competencias teniendo los objetivos perfectamente claros. Una educación teológica que no esté divorciada de los seres humanos de carne y hueso, que no se contente sólo con la reflexión, sino que vaya a la praxis. (Aldana, 2009, p. 80)
Para ello, la formación teológica busca dar testimonio del Evangelio, en diálogo con los hombres y mujeres de cada tiempo, en el compromiso de compartir la cultura del otro, en el establecimiento de códigos de mutuo entendimiento, de tal modo que, en el horizonte del acontecimiento Cristo, responda eficazmente a preguntas, problemas y cuestiones de envergadura para la humanidad y, en particular, para quienes interactúan en el proceso educativo teológico performativo (Silva, 2010), todo ello, en función del desarrollo armónico de sus dimensiones, asunto que bien podría ser entendido como formación integral.

En síntesis, la enseñanza teológica asume los elementos básicos de la enseñabilidad de los saberes, sin eclipsar lo propio de la teología. Por tanto, trata de acciones intencionadas por parte de un docente que, conociendo la disciplina teológica, procura comunicarla a unos destinatarios ubicados históricamente para que estos sean capaces de encontrar el sentido teológico de la realidad (expresada en inquietudes, problemas, temas, categorías, nociones, experiencias, hechos, entre otros). La enseñanza teológica, además, es mediación entre los actores implicados y las situaciones que se presentan. Ahí radica una de las razones de su dinamismo y actualización. Finalmente, la enseñanza teológica aglutina elementos propios de la didáctica -de la didáctica teológica, si se quiere- junto con los implícitos constituidos en el docente a lo largo de su experiencia educativa.

\section{Método}

La caracterización de las prácticas de enseñanza teológica ligadas tanto a los procesos de formación universitaria como a las experiencias de estudiantes y docentes requirió un abordaje cualitativo (Denzin y Lincoln, 2000). Además, como las prácticas de enseñanza son acciones complejas que impactan las dimensiones personal, interpersonal, institucional, social, didáctica y valorativa (Fierro, Fortoul y Rosas, 1999), el enfoque cualitativo facilitó 
la identificación de elementos inscritos en las prácticas de enseñanza teológica para su comprensión y su posible transformación. Con este enfoque, se consideró que el estudio de caso múltiple era el método más adecuado para dar cuenta del problema de investigación. Los estudios de caso tienen como característica básica el abordaje de forma intensiva de una unidad (persona, familia, grupo, organización o institución) para comprender dinámicas o fenómenos particulares. Siendo idiográfico, el estudio de caso genera conocimiento sobre experiencias de formación situadas en contextos locales al partir de evidencias empíricas.

De acuerdo con Stake (1999), los casos seleccionados pueden ser similares o diferentes, ya sea para entender las concordancias o las variantes entre ellos. En esta investigación se seleccionaron cuatro universidades de fundación e inspiración católica en las ciudades de Bogotá y Cali que ofrecieran asignaturas de índole teológica a estudiantes de toda la universidad: Pontificia Universidad Javeriana, sede Bogotá (PUJB), Universidad de La Salle (ULS), Universidad Católica Lumen Gentium (LG) y Pontificia Universidad Javeriana, sede Cali (PUJC).

Los sujetos participantes fueron: profesores (P) que hubieran orientado asignaturas teológicas en programas académicos distintos a los de teología en los últimos tres años; estudiantes (E) de programas académicos diferentes a la teología que hubieran cursado una o más asignaturas de índole teológica; y directivos (D) que tuvieran conocimiento sobre la propuesta de formación teológica de su universidad. El total fue de 137 informantes distribuidos así: Pontificia Universidad Javeriana de Bogotá: P: 7, E: 4O, D: 1; Universidad de La Salle: P: 5, E: 36;4 Universidad Católica Lumen Gentium: P: 4, E: 8, D: 3; Pontificia Universidad Javeriana de Cali: P: 11, E: 17, D: 5.

4 Por razones circunstanciales no fue posible llevar a cabo las entrevistas previstas con los directivos de la Universidad de La Salle. No obstante, en atención al principio de saturación, la información obtenida de los otros participantes fue suficiente para lograr el propósito de la investigación.
La recolección de datos se hizo a través de grupos focales con estudiantes y entrevistas semiestructuradas con profesores y directivos. La información recogida, gracias a ambas técnicas, facilitó su triangulación en el momento del análisis, el cual se llevó a cabo en la lógica del análisis de contenido basado en la teoría fundamentada en los datos (Gil, 1994; Glaser y Strauss, 1967). Atendiendo a dicho proceso se clasificaron, codificaron y categorizaron los datos haciendo uso de la herramienta informática Atlas.Ti. Los resultados del análisis permitieron hacer su interpretación en clave de aciertos e interpelaciones.

\section{Resultados, aciertos e interpelaciones}

Dentro del cometido de la investigación los hallazgos traen a colación las voces de los informantes (profesores, estudiantes y directivos). Además, la lectura analítica es categorial y transversal en torno a: concepción de la teología, percepción e intencionalidad de la formación teológica, contenidos y actividades didácticas desarrollados en los cursos de formación teológica.

\section{Concepciones acerca de la teología}

Los implícitos de la enseñanza teológica llevaron a considerar la noción que los profesores tienen acerca de la teología para revisar su relación con los modos de enseñanza. Al respecto, hay quienes consideran la teología como el estudio de Dios, en el cual intervienen la revelación y la fe: "la teología es ese tratado de lo sagrado, de lo sacro, de los misterios" (PUJB-P-1:25), "reflexión crítica de la revelación de Dios" (PUJB-P-1:35), "es la reflexión crítica y sistemática sobre la fe en dos dimensiones: la fe declarada y la fe vivida" (LG-P-1:10). Otros la inscriben estrictamente en las coordenadas cristiano-católicas: "yo trato de presentar el proyecto de opción por Cristo [...] y la propuesta cristiana católica, sobre todo, de la teología moral" (LG-P-2:4). En cambio, otros profesores poseen una concepción más cercana a una teología natural: "[la teología] es todo aquello que tiene contacto con lo trascendente" (ULS-P-1:10), 
"disciplina o área de conocimiento que les da la posibilidad a las personas de cuestionarse o preguntarse sobre el sentido y su existencia” (PUJB-P-1:12). Algunos le conceden un espíritu crítico: "desde una razón crítica, [la teología] lleva al sujeto a conocer los principios que se fundamentan en el evangelio de Jesucristo para actuar con convicción" (LG-P-2:6), y otros un espíritu práctico: "la teología no es un concepto ni ideas del magisterio, no es la ortodoxia, sino una teología viviente" (LG-P-2:1) que se hace "experiencia de Dios" (PUJB-P-1:1), que "abre los ojos de los estudiantes ante lo trascendente en sentido amplio y que les ayuda a encontrar un sentido profundo en sus vidas" (PUJC-P-1:17). Y unos pocos la asocian a los estudios de la religión: "la teología es un campo disciplinar que pone como objeto de estudio el hecho religioso, el fenómeno religioso, entendido como la expresión de los sistemas de creencias, prácticas y comprensiones de lo religioso" (ULS-P-1:9) y "no desde una perspectiva confesional o proselitista sino abierta, tanto antropología teológica como antropología religiosa [...] antropología en todo el sentido de la palabra" (PUJC-P-1:11).

Como se señaló anteriormente, la idea que se tenga de la teología no es ajena a su traducción en prácticas concretas. Así las cosas, la gama nocional ligada a la teología ayuda a comprender el énfasis que adoptan las prácticas de enseñanza en cuanto a determinadas intencionalidades, actitudes, contenidos o actividades. Sin embargo, ¿qué resulta de la diversidad de nociones expuestas? Recordemos, primero, que no existe una única definición de teología. Para ilustrarlo, viene bien recordar algunos conceptos contemporáneos citados por la teóloga Vélez (2008, p. 26): "la teología es la búsqueda de inteligibilidad del dato revelado a la luz de la fe o, más simplemente, la ciencia de Dios en la revelación" (Hitz); "teología es la actividad compleja del espíritu por la cual el hombre que cree busca penetrar mejor el sentido de lo que él cree para profundizarlo y comprenderlo mejor" (Adnès); y "las teologías son un esfuerzo de traducción para la razón (doc- trina), para la práctica (ética) y para la celebración (liturgia) de esta experiencia fundante, a saber, el encuentro con Dios que envuelve la totalidad de la existencia, el sentimiento, el corazón, la inteligencia, la voluntad" (L. Boff). No obstante, aunque guarden diferencia, resulta común que la teología trata de una reflexión creyente de la autocomunicación de Dios (revelación).

Si esto es así, valdría la pena que cada institución realizara una lectura crítica de aquello que ha llamado formación teológica porque, si ella es "teológica", no debería sacrificar lo constitutivo de la teología y confundirlo con lo que sería más propio de la filosofía de la religión, la fenomenología religiosa o los estudios de la religión. En otras palabras, la institución -sobre todo, sus profesores- ha de reflexionar sobre su apuesta teológica y, si se quiere, sobre el tipo de teología que pretende enseñar.

\section{Percepciones sobre la formación teológica}

Una lectura diferenciada de la percepción sobre la formación teológica de los informantes señala que profesores y directivos consideran que existe una prevención por parte de los estudiantes que va disminuyendo a medida que transcurre el semestre. En esto coinciden las instituciones participantes: "llegan muy prevenidos y muchos de esos falsos imaginarios sobre la teología se van cayendo durante el curso. Al final puede haber expresiones como: "profesor, gracias por volver la teología interesante"' (PUJC-P-1:3; en términos similares: PUJB-P-1:4; LG-P2:6). La prevención disminuye porque, si encuentran apertura, "ven que los temas tienen que ver directamente con sus vidas" (PUJC-P-1:2) o hallan una oportunidad para ver algo nuevo y diferente y "hay una avidez de conocimiento" (PUJC-P-1:9). Sin embargo, no falta quien tenga una mirada más optimista: "a la mayoría les atrae, les cautiva, no falta pues el indiferente frente a la cuestión de Dios, frente a la propuesta religiosa, pero a la mayoría les interesa y quieren profundizar más al respecto" (LG-P-2:4). 
Adicionalmente, directivos y profesores encuentran estudiantes que no tienen interés por las asignaturas teológicas, que cursan porque son obligatorias: "[a] la mayoría de los estudiantes no les interesa [...] porque consideran que los únicos contenidos que debieran recibir son los disciplinares" (LG-P-1:7), o porque "el estudiante de entrada los cree cursos de relleno, por lo tanto, está desmotivado y siente que es una cosa obligatoria y que nada tiene que ver con su disciplina" (LG-D-1:7).

No obstante, algunos directivos perciben que la formación teológica y humanistica es un elemento que incide en la opción por la universidad: "cuando hablamos con los padres de familia dicen que, definitivamente la formación humanística, en teología, es una formación especial y distinta en la Universidad. Es lo que atrae, llama la atención y por eso deciden matricularlos aquí y no en otra universidad" (PUJC-D-1:7).

Por su parte, los estudiantes corroboran la prevención percibida por los profesores. Algunos porque creen que los cursos son espacios de adoctrinamiento - "yo venía con la concepción de que íbamos hablar netamente de lo católico" (LG-E-1:2) - y luego descubren que son espacios de formación humana: "para mí, pues, me han hecho ser mejor persona, coger por un buen camino y de pronto tener conciencia, tener una postura crítica" (LG-E-1:10); de crecimiento axiológico: "dentro de ellas también había mucha formación en valores" (LG-E-1:1); de conocimiento de la realidad social para tener un rol activo en su transformación: "esta clase nos ha permitido acercarnos a las problemáticas sociales de nuestro país. Nosotros estamos trabajando en tres fundaciones" (ULS-E-1:8).

Sin embargo, en algunos casos no se logra este cometido. Uno de los estudiantes señala: "pues, me parece que las materias deberían ser más aterrizadas a nuestra realidad, concentrándose en cosas más actuales" (LG-E-1:11). Otros consideran que no tienen un talante crítico: "me parece preocupante que nos den materias que no generan un tipo de pensamiento crítico" (PUJB-E-3:2); o quisieran que fuera un espacio sin mayores exigencias: "se espera que estos espacios sean algo que le ayuden a uno a despejarse del diario vivir. Sobre todo, para los estudiantes de la noche no es tan divertido venir a clase" (ULS-E-1:3).Y otros se sienten excluidos porque niegan su confesión religiosa: "por ejemplo, yo soy cristiana protestante y de alguna manera siento que el enfoque que le dan es muy católico" (ULS-E-1:5).

En términos generales, los estudiantes saben que la institución a la cual se matriculan ofrece cursos de formación teológica que hacen parte del núcleo fundamental de sus programas. Así las cosas, tratándose de una condición, la universidad católica debería ir más allá del argumento de autoridad y comunicar creativamente la importancia de dicha formación en el florecimiento de lo humano o, si se quiere, en la promoción de la dimensión trascendente en relación con otras, como la afectiva, social, política, ecológica, estética, comunicativa. Si vamos más allá, hemos de adicionar la dimensión ecuménica e interreligiosa, tan necesaria en estos tiempos de pluralidad, diálogo y reconocimiento de la diferencia.

Tal vez no se trate del qué sino del cómo; de la manera como se puede aminorar la prevención hacia lo teológico y, en cambio, favorecer una mayor aceptación al presentar su aporte claramente. En este sentido, habría que imaginar estrategias que desdibujen preconceptos amañados o prejuicios sin fundamento. Con todo, no podemos ser ingenuos frente a la idea profesionalizante de los currículos y el proceso de secularización en el cual nos encontramos.

\section{Intencionalidades de la formación teológica}

La diversidad de concepciones teológicas y percepciones acerca de la formación teológica puede ayudar a comprender el abanico que se abre con respecto a su intencionalidad. La coincidencia más relevante está en que los estudiantes, profesores y directivos señalan que la razón de la presencia de la teología en el currículo es contribuir a la formación integral de los estudiantes: "[la formación teoló- 
gica] aporta a la formación integral y hace que el estudiante encuentre el sentido de su vida" (ULSP-1:5), "les permite tener una formación integral, reconociendo su relación con Dios, consigo mismo, con los otros y con el medio ambiente desde los valores cristianos y la supremacía de la dignidad humana" (LG-D-1:1).

También coinciden en afirmar que la formación teológica conlleva una propuesta de educación en valores. Un directivo afirma: "esta es una institución confesional (...) que ha asumido como parte de su misión la formación desde los valores cristianos" (LG-D-1:3). Un profesor remarca: "la propuesta, en el caso de nuestra facultad, es una apuesta por el sentido de vida, pero no cualquiera, sino un sentido de vida animado por los valores cristianos" (PUJB-P-1:8). Los estudiantes también lo dicen: "la Universidad nos convierte no solo en profesionales sino también en personas que tengan unos valores morales" (ULS-E-1:16).

Aunque en menor medida, algunos informantes coinciden en afirmar que la intención de las asignaturas es cultivar una mirada crítica de la realidad social: "la teología aporta otra perspectiva de comprensión o de interpretación científica sobre la realidad que, obviamente, en mi opinión es crucial para enriquecer la experiencia de la vida de la existencia misma" (LG-P-1:5). No obstante, llama la atención que los estudiantes hagan énfasis en la dimensión sociopolítica de la formación teológica: "considero que la universidad se enfoca mucho en lo social y creo que estos cursos nos ayudan, no solamente a hacer tu carrera, sino también a ayudar a la sociedad" (PUJB-E-1:10).

Por parte de los docentes, cabe señalar otras intencionalidades, como que los estudiantes se den cuenta del aporte que puede hacer la teología en el diálogo interdisciplinario a la hora de responder a diversos problemas: "hay muchos temas que son interdisciplinarios, por ejemplo, la defensa de la vida, los valores, los derechos humanos, el derecho interna- cional humanitario, [...] todos esos temas tienen una propuesta cristiana católica. A ellos les sirve para su formación" (LG-P-1:10). Para otros docentes lo importante es enseñar a "pensar teológicamente" (PUJBP-1:15) y a "desmitificar el concepto simplista de que la teología es el estudio de Dios" (PUJB-P-1:1).

Los informantes reiteran que la presencia de la teología en sus planes de estudio se debe a la formación integral, por lo que comunica una propuesta axiológica y promueve una mirada crítica de la realidad. Aunque esto puede resultar válido, cabe preguntarse si esta no es la misma intención de otros espacios humanísticos y sociales. O, más todavía, ¿para qué desgastarse en proponer una formación teológica que olvida lo que le es más propio y particular? Tal vez lo teológico se presenta tímidamente debido a las prevenciones que ya se exponían arriba. La pregunta que da que pensar es: ¿cómo lograr los propósitos de la formación teológica sin renunciar a la teo-lógica? Uno de los informantes lo señaló con lucidez: "se trata de pensar teológicamente la realidad, nuestra vida, nuestras experiencias, nuestra historia". Solo así los estudiantes se darían cuenta de la valía de la teología como disciplina sapiencial.

\section{Contenidos de la formación religiosa}

Si existen diferentes concepciones de teología, formación teológica e intenciones, podemos imaginar que también su contenido es diverso. La procura de un diálogo entre fe y ciencia, fe y cultura, y fe y vida configura diferentes contenidos. De hecho, los nombres de las asignaturas sugieren cercanía con los estudios de la religión, la espiritualidad, la teología cristiano-católica, el magisterio de la iglesia católica romana, la doctrina social, la antropología, la sociología, la economía, la política, la salud, la ética o la axiología. Parece que todo depende de las apuestas institucionales, pero, sobre todo, de las urgencias o los implícitos de la enseñanza de los profesores.

Estudios de la religión. Uno de los directivos señala: "como institución de educación superior reco- 
nocemos que la religión es un hecho de la cultura y, en cuanto tal, merece ser estudiada" (PUJB-D-1:39), afirmación refrendada por los estudiantes de la misma universidad: "nos enfocamos en ver las religiones del mundo y, más específicamente, en lo que es el cristianismo y cómo el arte se introdujo en esta religión para hacerse conocer de las personas" (PUJBE-1:3). Cabe resaltar que el estudio de las religiones en relación con la cultura es un tema común en las universidades participantes.

Espiritualidad. Se percibe cierta preferencia por tratarse de un tema que, a diferencia del carácter objetivo, empírico e ilustrativo de la religión, puede tocar al sujeto en su existencia. Incluso, algunos consideran que presenta menos resistencia. No obstante, en algunos casos se emparenta la religiosidad con la espiritualidad: "aprender de espiritualidad, de religión como tal, a uno le sirve para ayudar a entender la persona" (PUJC-E-1:1). En otros casos los estudiantes logran identificar las implicaciones de la espiritualidad con otros asuntos: "la espiritualidad ecológica presenta una reflexión clara de toda la problemática ambiental" (PUJC-P-1:12).

Teología natural, cosmología y diálogo fe-ciencia. Algunos profesores consideran importante problematizar a los estudiantes a partir de lo que ven, viven y aprenden. Por eso, les proponen preguntas que tienen que ver con el ser humano, su lugar en la historia, el cosmos y su origen, la idea de un ser supremo y su relación con la realidad, junto con las respuestas de la ciencia a las preguntas del existenciario humano: "yo trabajo mucho lo que son temas científicos en diálogo con la fe. Me gusta trabajar lo que yo llamo teología natural, teología revelada y neurociencia" (LG-P-1:8).

Temas de actualidad. Otros profesores prefieren abordar en sus clases temas de actualidad ya como pretexto o ya como contenido. Un profesor dice: "todos mis temas son prácticos. Yo les pregunto cómo va su afectividad, su sexualidad, cómo ejercen el tema de la defensa de la vida, la ecología, el impacto ambiental. Son temas de actualidad" (LG-P1:7). Un estudiante lo corrobora: "en la clase, por lo general, nos enseñaban temas de la actualidad, por ejemplo, el aborto, lo que hacen con las partes de los fetos [...] también vimos bioética" (LG-P-1:30).

Humanismo y sensibilidad social. En algunos casos enfatiza en lo humano y lo social: "en mis clases trato de que la persona empiece a darse cuenta de qué es lo humano" (ULS-P-1:1), "que ellos sean capaces de poner en diálogo los elementos con lo que están viviendo" (PUJB-P-2:10); "allí trabajamos lo que tiene que ver con transformación y el sentido de vida" (ULS-P-1:9). Los estudiantes así lo perciben: "hemos reflexionado sobre la problemática social actual, lo que estamos viviendo en Colombia y en los países latinoamericanos" (ULS-E-1:6); "vimos formas y soluciones a la violencia, cómo se han configurado mecanismos sociales con bases inhumanas" (PUJB-E-1:2).

Cristología e historia de Jesús. Aunque algunos reportan contenidos referidos al Jesús histórico y al Cristo de la fe, no son temas axiales. Son más un pretexto para hablar de la realidad actual: "veo el contexto histórico y político en el que se desarrolló la propuesta Jesús de Nazareth, el Reino de Dios, para luego hacer un paralelo entre esa época en la que se vivía bajo la dominación del Imperio Romano y nuestro contexto actual colombiano" (PUJC-P-1:7). Los estudiantes lo leen casi de la misma forma: "vimos ciertas consideraciones acerca del Reino de Dios y lo que predicaba Jesús. De ahí salían a la luz bastantes principios que son posibles en la sociedad actual occidental, digámoslo así, como sería la compasión" (PUJC-E-1:3). En términos generales, algunos recurren a las narrativas bíblicas para ilustrar temas actuales diversos.

Magisterio eclesialy doctrina social de la Iglesia. En algunos cursos ocupa un papel predominante el magisterio de la iglesia católica: "Desde el discurso, hablamos de la doctrina social de la iglesia para psicología [...]. Vemos a Lacan metido en el problema 
de las exhortaciones apostólicas" (LG-P-2:13); "la Laudato Si' es el texto central, porque es lo que estamos viviendo hoy. La problemática de lo que está pasando en el mundo de hoy impacta al joven, la contaminación, cómo tenemos el planeta" (PUJC-P-1:10). Por su parte, los estudiantes hacen una lectura más institucional: "en el curso de doctrina social se nos muestran los principios propiamente de la iglesia católica, lo que debe seguir una persona católica" (LG-E-1:6). En un sentido más amplio, algunos hacen referencia a la labor de la iglesia frente a las problemáticas sociales e invitan a sus estudiantes para que se vinculen a alguna iniciativa: "en el curso van a trabajar con organizaciones de tipo social para ver cómo la Iglesia ha respondido a las necesidades de tipo social" (ULS-P-1:8).

Ética y axiología. La naturaleza teológica de los cursos permite traspasos a otros campos, como el de la ética, con vinculación a la teología moral y la axiología: "nos ponían a leer con el fin, no solo para verlo todo alrededor de la religión, sino para ver cómo se aplica a la moral y la ética de las personas que estamos haciendo estas carreras" (PUJC-E-1:4).

Finalmente, vale la pena señalar que algunos estudiantes, a pesar de la variedad temática, consideran que los contenidos no hacen un aporte mayor a su formación personal ni profesional: "la verdad no veo ninguna relación con los temas que hemos visto [...]. Siento que no me aportan como artista" (PUJBE-1:6); "tampoco me aporta mucho, pues yo nací en una cuna cristiana y tengo conocimientos [...]. Es chévere saberlo como datos curiosos, pero a mí, realmente, no me aporta ni a mi carrera" (PUJB-E-1:8).

No hay duda de que estos contenidos pueden resultar interesantes tanto para estudiantes como para profesores y, además, pueden ser un buen pretexto para lograr el propósito que busca la formación teológica según sea su concepción. Empero, ¿es posible enseñar teología sin referencia a Dios? ¿o teología cristiana sin Jesucristo?, ¿o una visión cristiana del hombre sin Evangelio?, ¿o una moral cristiana soslayando los valores del Reino? A nuestro modo de ver, esto no es posible. Más todavía, la universidad católica está llamada a revisar si no existe acaso una actitud vergonzante ante su propuesta $y$, por tanto, prefiere proponer otros temas que, aunque sean más atractivos, velan el mensaje de Cristo y dejan la impresión de que no fuese vigente ni tuviera la fuerza para ser presentado a las nuevas generaciones. Por tanto, queda por ver si en realidad la formación logra lo señalado por uno de los directivos: "[los cursos de teología] exponen una visión cristiana del ser humano, de la sociedad y de la relación con Dios" (PUJB-D-1:42).

\section{Didáctica de la formación teológica}

¿Qué es lo propio de la enseñanza teológica? ¿existe diferencia entre la didáctica teológica y la de otras disciplinas? ¿prevalecen en la teología modos de enseñanza de otras disciplinas?, ¿ha incorporado para sí los avances de la didáctica especializada moderna? Los hallazgos no resuelven del todo estas preguntas, pero muestran el uso preponderante de la clase magistral, el diálogo, el trabajo colaborativo y las exposiciones de los estudiantes. En este sentido, algunas técnicas se inclinan por una didáctica centrada en el docente o, en contraposición, una didáctica centrada en el estudiante (Laudadío y Da Dalt, 2014):

Clase magistral. Fiel heredera de sus orígenes universitarios, la lectio sigue ocupando un lugar importante en la didáctica teológica, ya sea de forma pura o combinada: "por lo general su clase es magistral y de vez en cuando hace una actividad" (PUJBE-1:1); "normalmente traigo una lectura de periódico o de revista, o un resumen de algún libro, y luego voy al segundo paso, que no lo he podido quitar, que lo tengo en muchos años de experiencia, que es la clase magistral" (ULS-P-1:2); "hay un componente que es magistral, también hacemos exposiciones, investigación, trabajos en grupo" (LG-P-1:4); “ "siempre tengo mi homilía, mi sermón preparado, que lo traigo en cuartos de cartulina con letra muy grande" (ULS- 
P-1:18). De la clase magistral se infiere un rol pasivo por parte del estudiante. Él escucha, atiende y toma nota o, lo que es peor, se pierde: "a veces me duermo en las clases, porque es muy aburrida. Personalmente a mí me gustan más esas clases en donde nos incluyen a nosotros y no la clase aislada" (ULS-E-1:6).

Diálogo. En cambio, si existe la posibilidad de interpelar al estudiante, su rol se hace activo y, seguramente, más motivante: "me gusta muchísimo que nos pone a hablar. Nos pregunta a todos qué pensamos al respecto. Él da un ejemplo y nos involucra en el ejemplo" (ULS-E-1:12); "a través de un proceso mayéutico, de pregunta y repuesta, logramos ver la diferencia" (PUJB-P-1:6).

Trabajo colaborativo. El trabajo realizado con la participación de todo el grupo o en pequeños grupos durante la clase o entre clases también es una estrategia común en las clases de teología: "los temas del libro los desarrollamos en grupo. Hay exposiciones grupales” (ULS-P-1:12); “también leen con un soporte, responden el taller grupal y elaboran una cartelera" (PUJB-P-1:8).

Exposiciones de los estudiantes. El trabajo colaborativo conlleva exposiciones de los estudiantes. Esta estrategia es común en todas las instituciones: "la idea es que los estudiantes puedan hacer una exposición, no para repetir el texto, sino para que conecten las ideas con una situación personal de vida" (PUJB-P-2:12). Los estudiantes creen que es una buena oportunidad para aprender y ser creativos: "me parece importante que nos permite hacer exposiciones frente a diferentes problemáticas o temas. Me parece súper chévere" (PUJB-E-1:8).

Lectura de estudio. Antes de la clase, durante o después de ella, los profesores proponen a los estudiantes una o varias lecturas de estudio. Dichas lecturas se convierten en un pretexto de aprendizaje o en insumo para la discusión: "siempre en los temas del programa se tiene una lectura base. No siempre la evaluó, no siempre hago talleres, pero siempre hay una lectura base" (PUJB-P-1:10). Los estudiantes así lo confirman: "están los informes de lectura que él nos mandó. En el formato estaba lo que entendimos y lo que no entendimos" (PUJB-E-1:15). El uso de lecturas impresas (libros, revistas, fotocopias) ha venido a menos; en cambio, son más frecuentes las lecturas en formato digital ( $p d f$, repositorios en la nube, plataformas, textos en la web, etc.).

Un poco menos, pero de forma significativa, se aprecia el uso de estrategias como relatos autobiográficos y narrativas personales: "es interesante cuando ellos hacen un ejercicio autobiográfico en el cual cuentan alguna experiencia que los ha marcado a nivel religioso o espiritual, positiva o negativamente. Ahí uno descubre que hay cosas que suceden en su familia" (PUJC-C-1:6); salidas de campo, visitas sociales y lugares de culto: "las visitas a comunidades empobrecidas o a fundaciones las ligan a la cátedra. Me parece que eso es interesante por la sensibilización y el compromiso frente al contexto" (LG-D-1:15); "las clases han permitido que los estudiantes conozcan lugares de culto distintos al católico, donde sus líderes religiosos han compartido su experiencia de fe y donde el estudiante indaga sobre asuntos desconocidos para él [...]. Esto ha generado un clima de respeto por los cultos distintos al cristianismo" (LGD-1:6); y conversatorios con invitados o expertos: "los conversatorios con distintas tradiciones religiosas, con un pastor, un imán, un rabino, un presbítero, qué se yo, les permite conocer la variedad de tradiciones" (LG-D-1:16).

En cuanto a los recursos, vale la pena señalar el uso de un libro base: "en mi curso uso el libro de Pagola. Es muy denso, pero también hay una versión más breve" (ULS-P-1:8); "uno de los textos de mi clase se llama Del ateísmo a la fe cristiana: la experiencia de conversión de un biólogo. Ahí trato de relacionar mi experiencia personal con contenidos teológicos que tienen que ver con el fenómeno de la conversión" (LG-P-2:12). Aquí vale la pena reiterar que algunos -tal vez pocos- hacen uso de la Biblia o documentos eclesiales. 
También se hace uso de elementos visuales y auditivos como obras de arte: "hay una actividad sobre la iconografía cristiana en el Renacimiento. El ejercicio consiste en que los chicos vayan y busquen una imagen, una pintura de la época del Renacimiento donde aparezca un pasaje de la historia de Jesús" (ULS-P-1:9); documentales: "uso documentales que muestran la realidad social de Colombia, escenas impactantes de noticieros [...] o documentales sobre responsabilidad social" (PUJB-P-1:8); películas y videoclips: "vimos una película que se llama Ágora en la que se muestra el conflicto entre cristianos y paganos" (ULS-E-1:7); web 2.0 y 3.0 con varios de sus recursos: "yo tengo toda mi formación en la nube. Tengo un blog donde tienen los links en los que ellos se pueden meter. Toda la información de mi área está en las páginas del Vaticano, en las páginas que hay de bioética y en los links de muchas ONG" (LG-P-2:9).

Elaboración de escritos y trabajos alternativos. Algunos profesores proponen a los estudiantes la elaboración de ensayos, papers o trabajos escritos. Otros, con algo de inventiva, plantean la creación de productos análogos y visuales: "el profesor al final de cada corte nos hace hacer una revista que consiste en relacionar lo que vimos en cada clase con un aporte personal [...]. Eso es lo que más me gusta de toda la materia, porque en la revista uno puede poner lo que piensa de todo lo que vimos, si estás de acuerdo, si no estás de acuerdo" (ULS-E-1:13). Otros motivan la creación de elementos artísticos: "le puse [al ejercicio] el nombre de 'Jesús en el Arte'. Consiste básicamente en que cada estudiante busque o cree una obra de arte. Puede ser una canción, una pintura, una poesía, un collage sobre la vida de Jesús" (ULS-P-1:10). Y otros promueven la elaboración de rúbricas: "elaboro un formato para que llenen sesión por sesión. La intencionalidad del formato es que escriban aquellas ideas que les puede servir" (PUJB-P-2:14).

Si quisiéramos establecer una secuencia didáctica a partir de estos datos, se perciben algunos momentos como: recapitulación, sensibilización, fundamentación-explicación y aplicación. En la re- capitulación, algunos profesores piden a los estudiantes recordar lo visto en la clase anterior. En la sensibilización se presentan elementos que sirven de motivadores o problematizadores frente al tema que se va a desarrollar. La fundamentación-explicación es aquel momento en el que, ya de forma magistral o de forma interactiva, se presentan los elementos teóricos y prácticos del tema. Al final, se da un momento de cierre en el cual se buscan las implicaciones o la aplicabilidad del tema visto $y$, además, su evaluación. Se aclara que esta secuencia didáctica no fue reportada por los participantes. Sus elementos aparecen fragmentariamente.

Con todo, vale la pena preguntarse: ¿tiene la teología una didáctica especial? Si la tuviese ¿qué la caracterizaría?, ¿qué sería lo propio de un método de enseñanza teológica? En términos generales, lo expuesto parece una apropiación de actividades y recursos presentes en la enseñanza de otras disciplinas. La lección magistral parece identificar la enseñanza teológica desde sus orígenes, pero ¿no sería necesario explorar otras modalidades? Como este asunto no es menor, la universidad católica está llamada a pensar la pedagogía de la teología y, específicamente, la didáctica de la clase en educación superior considerando el propósito de tipologías contemporáneas como la clase-práctica y la claseencuentro (Hernández y Infante, 2017).

Pero, atención, la didáctica ha de ser consecuente con su noción de teología y su apuesta formativa. Si estas quisieran suscitar o fortalecer una experiencia de fe, ¿la didáctica no debería ser experiencial?; si pretendieran una lectura crítico-reflexiva de la relación fe-ciencia, ¿no sería acaso una didáctica crítica e interdisciplinaria la más apropiada? En otras palabras, lo que se ve grosso modo es una fractura entre el qué y el cómo, entre lo que se busca y la manera de lograrlo. Recuérdese, la didáctica no es un recetario de actividades y recursos, no es un know-how. La didáctica es una acción en la que convergen el saber, el enseñante y el estudiante en una relación transformadora y única. ¿Qué es eso único 
con sabor teológico que debe ocurrir en cada clase?, ¿qué es lo propio y particular de la enseñanza teológica? Según De Vincenzi (2009), una clave estaría en la revisión de las concepciones de enseñanza en relación con las prácticas docentes.

\section{Conclusión}

La didáctica teológica, en cuanto didáctica, no es ajena a las construcciones metodológicas que promueven el aprendizaje en los estudiantes en una articulación inteligente entre propósitos, contenidos, secuencialidad, formas de enseñanza, recursos y evaluación; y, en lo teológico, trata de acciones intencionadas por parte de un docente para que los estudiantes aprendan a pensar teológicamente y sean capaces de encontrarle el sentido teológico a la realidad, cualquiera que sea su texto (temas, problemas, fenómenos, experiencias) en relación con un contexto determinado.

Ahora bien, frente al esfuerzo de las universidades católicas para que en su propuesta curricular tengan lugar espacios de formación teológica, los profesores no solo son conscientes de su responsabilidad, sino que diseñan formas para llegar de mejor manera a los estudiantes. Sin embargo, ¿logran su propósito formativo? Aunque en la mayoría de los casos los prejuicios y prevenciones de los estudiantes son fracturados en la procura de clases agradables, al final la teología resulta extraña o queda diluida entre asuntos religiosos, espirituales y morales. Incluso, en el trabajo interdisciplinario de la clase, tan necesario en la academia, el componen- te teológico parece pasar a un segundo plano y, en cambio, adquieren fuerza elementos propios de las ciencias humanas y sociales.

Con todo, vale la pena resaltar que las prácticas de enseñanza tienen un alto grado de contextualidad. La formación integral y axiológica no ocurre en el vacío; por el contrario, se procura a expensas de los problemas humanos, sociales, políticos, económicos y ecológicos.

Este polo a tierra es una de las variables que incide en la disminución de las resistencias que pudiera haber por parte de los estudiantes. En el diálogo de la teología con la vida y la cultura, aquella cobra un papel relevante al captar su interés, cualquiera que sea su condición creyente. De hecho, la reflexión sobre la vida y la cultura, en un sano humanismo, podría ser la estrategia para llegar a los estudiantes en estos tiempos de secularización y apatía por lo religioso.

¿Qué sería lo propio de la enseñanza teológica?, ¿cuáles deberían ser sus implícitos? Si la enseñanza teológica es pertinente a las necesidades de las personas y del contexto, capaz de visualizar los signos de los tiempos, de anunciar y denunciar, de encarnarse en el corazón de los estudiantes y ayudarles a desarrollar sus capacidades teniendo los objetivos perfectamente claros, y de reflexionar acerca de lo que (nos) acontece, sabiendo que allí habla Dios, ¿lo está consiguiendo? Más aún, ¿tales prácticas logran que la reflexión se convierta en una praxis transformadora perdurable en clave de Reino de Dios? Aquí radicaría su valentía. 


\section{Referencias}

Aldana, R. (2009). Desafíos de la educación teológica. Teología y Cultura, 10, 69-81.

Andraos, M. E. (2012). Engaging diversity in teaching religion and theology: An intercultural, de-colonial epistemic perspective catholic". Teaching Theology and Religion, 15(1), 3-15. DOI: https://doi.org/10.1111/j.14679647.2011.00755.x

Aranda, A. (2015). Teología y universidad en el contexto de la nueva evangelización. Pontificia Academia Theologica, 14, 9-22.

Arteaga, A. (2002). Teología en la Universidad. Teología y Vida, 43(1), 5-20. DOI: https://doi.org/10.4067/Soo4934492002000100002

Basabe, L. y Cols, E (2008). La enseñanza. En De Camilloni, A., Cols, E., Basabe, L. y Feeney, S., El saber didáctico. Buenos Aires: Paidós.

Bidlack, B. et al. (2014). Teaching comparative theology from an institution's mission". Teaching Theology and Religion, 17(4), 369-387. DOI: https://doi.org/10.1111/teth.12247

Burbules, N. (1999). El diálogo en la enseñanza Teoría y práctica. Buenos Aires: Amorrortu.

Cárdenas Pérez, A. V., Soto-Bustamante, A. M., Dobbs-Díaz, E. y Bobadilla Goldschmidt, M. (2012). El saber pedagógico: componentes para una reconceptualización. Educación \& Educadores, 15(3), 479-496. https:// www.redalyc.org/articulo.oa?id=83428627008.

Cordovilla-Pérez, A. (2014). Teología y sociedad. En En defensa de la teología. Una ciencia entre razón y el exceso (pp. 34-53). Salamanca: Sígueme.

Cortina, A. (2013). Ser profesionales, no sólo tecnólogos. En ¿Para qué sirve realmente...? La ética (pp. 129-142). Barcelona: Paidós.

De Camilloni, A. (2012). El saber didáctico. Buenos Aires: Paidós.

De Vincenzi, A. (2009). Concepciones de enseñanza y su relación con las prácticas docentes: un estudio con profesores universitarios. Educación \& Educadores, 12(2), 87-101. https://www.redalyc.org/articulo.oa?id=83412219006.

Denzin, N. y Lincoln, I. (dirs.) (2000). Handbook of qualitative research. Londres: Sage.

Edelstein, G. (2011). Formar y formarse en la enseñanza. Buenos Aires: Paidós.

Francisco (2011). Constitución apostólica Veritatis Gaudium. Sobre las universidades y facultades eclesiásticas. Vaticano: Editorial Vaticana. 
Fierro, C., Fortoul, B. y Rosas, L. (1999). Transformando la práctica docente. Una propuesta basada en la investigación-acción. México: Paidós.

Gajardo, M. (2008). Elicitando teorías implícitas sobre la enseñanza y el aprendizaje en formadores de profesores y estudiantes de Pedagogía en Educación General Básica. [Tesis doctoral] Santiago de Chile, Pontificia Universidad Católica de Chile.

Garanzin, M. (2016). Is christianity irrelevant and extreme? En Jornadas de reflexión sobre pedagogía y evaluación en la teología. Bogotá. Literatura gris.

Garcez-Leme, M. C. (2008). La interculturalidad y la dialogicidad en el proceso de aprendizaje-enseñanza de la Teología. Siwố. Revista de Teología, 1, 75-97.

Gil-Flores, J. (1994). Introducción al análisis de datos cualitativos. Barcelona: PPU.

Glaser, B. y Strauss, A. (1967). The discovery of grounded theory. Chicago: Aldine.

Harrison, J. R. y Debergue, Y. (2015). Teaching theology in a technological age. Newcastle upon Tyne: Cambridge Scholars.

Hernández-Infante, R. C. y Infante-Miranda, M. E. (2017). La clase en la educación superior, forma organizativa esencial en el proceso de enseñanza-aprendizaje. Educación y Educadores, 20(1), 27-40. DOI: https://doi. org/10.5294/edu.2017.20.1.2

Jaramillo, J. (2005). Prácticas de enseñanza. En Gaitán, C., Campo, R., García, L., Granados, L. F., Jaramillo, J. y Panqueva, J., Prácticas educativas y procesos de formación en la educación superior. Bogotá: Pontificia Universidad Javeriana.

Juan Pablo II (1990). Constitución apostólica Ex Corde Ecclesiae. Sobre las universidades católicas. Vaticano: Editorial Vaticana.

Kenney, J. (2015). Teaching religious studies at the International Islamic University in Malaysia. Teaching Theology and Religion, 18(3), 280-285. DOI: https://doi.org/10.1111/teth.12296

Laudadío, M. J. y Da Dalt, E. (2014). Estudio de los estilos de enseñanza y estilos de aprendizaje en la universidad. Educación \& Educadores, 17(3), 483-498. DOI: https://doi.org/10.5294/edu.2014.17.3.5

López, E. (2002). Enseñar teología como tarea pastoral. Theologica Xaveriana, 142, 249-256. https://revistas.javeriana.edu.co/index.php/teoxaveriana/article/view/20921

Mafla, N. (2004). Percepción del estudiante javeriano de pregrado sobre el Servicio de Formación Teológica. [Tesis de Maestría] Bogotá, Pontificia Universidad Javeriana, Facultad de Teología.

Meza, J. L. (1999). Apuntes para una teología de la educación a partir de la Encíclica Fides et Ratio de Juan Pablo II. Theologica Xaveriana, 130, 161-168. 
Nussbaum, M. (2010). Educación para la renta, educación para la democracia. En Sin fines de lucro (pp. 33-49). Madrid: Katz. DOI: https://doi.org/10.2307/j.ctvndv6oc.6

O'Callaghan, P. (2015). The role of theology in the promotion of a pluralistic university. Pontificia Academia Theologica, 14, 69-93.

Pachón S.J., A.N. (2008). Misión y Universidad: ¿qué futuro queremos? [Conferencia] 50 años de la escuela de negocios Esade, Barcelona, 12 de noviembre de 2008. https://www2.ucc.edu.ar/archivos/2015/Coleccion\%20 Raices\%20de\%2oFuturo/raices-de-futuro-vol-2.pdf

Peresson, M. (2004). El lugar histórico-social y pedagogía de la teología de la educación. En La pedagogía de Jesús (pp. 23-25). Bogotá: Ediciones Salesianas.

Pontificia Universidad Javeriana (2013). Evaluación de la percepción del Servicio de Formación Teológica. Bogotá: Facultad de Teología.

Rodrigo, M. J, Rodríguez, A. y Marrero, J. (1993). Las teorías implícitas: Una aproximación al conocimiento cotidiano. Madrid: Visor.

Saines, D. (2009). How do students learn theology? Teaching Theology and Religion, 12(4), 333-347. DOI: https:// doi.org/10.1111/j.1467-9647.2009.00547.x

Sánchez, S. y Jiménez, J. M. (2015). El gran reto de la universidad (católica). Pontificia Academia Theologica, 14, 117-127.

Sebá, H. (2000). Universidad, teología y pedagogía. Theologica Xaveriana, 136, 487-496.

Silva-Soler, J. (2010). Pedagogía de la enseñanza teológica: La condescendencia de Dios como clave hermenéutica fundamental para la enseñanza teológica. Teología y Vida, 51(1-2), 233-255. DOI: https://doi.org/10.4067/ So049-34492010000100009

Stake, R. (1999). Case studies. En Denzin, N. y Lincoln, Y. (dirs.), Handbook of qualitative research (pp. 236-247). Londres: Sage.

Suriani, B. (2003). Las prácticas de enseñanza en contextos de cambio: características, dilemas y tensiones. [Congreso Latinoamericano de Educación Superior en el siglo XXI], San Luis, Argentina: Universidad Nacional.

Thivierge, G-R. (2012). La teología en la Universidad Católica. Revista Alberto Magnus, 1(1), 35-53. DOI: https://doi. org/10.15332/s2011-9771.2012.0003.04

Togarasei, L. (2015). Teaching and Learning Theology and Religion at the University of Botswana. Teaching Theology and Religion, 18(3), 271-275. DOI: https://doi.org/10.1111/teth.12294

Torres-Santomé, J. (1994a). Legitimación y discurso científico en educación. En El currículo oculto (pp. 22-32). Madrid: Morata. 
ISSN 0123-1294 | e-ISSN 2027-5358 | Educ.Educ. Vol. 24. No.3 | Agosto-octubre de 2021 | e2432

Universidad de La Sabana | Facultad de Educación

Torres-Santomé, J. (1994b). Prácticas tecnocráticas en la escuela y poder. En El currículo oculto (pp. 32-48). Madrid: Morata.

Valdrini, P. (2015). Il ruolo della teologia nell'universita cattolica. Pontificia Academia Theologica, 14, 149-157.

Vélez, O. C. (2008). El método teológico. Fundamentos, especializaciones y enfoques. Bogotá: Pontificia Universidad Javeriana.

Walton, H. (2012). The course outline: Teaching theology through creative writing. Journal of Adult Theological Education, 9(2), 210-218. DOI: https://doi.org/10.1179/ate.9.2.pt25581169181731

Woolfolk, A., Davis, H. y Pape, S. (2006). Teachers' knowledge, beliefs, and thinking. En Alexander, P. y Winne, Ph. (eds.), Handbook of Educational Psychology (pp. 715-737). Mahwah, NJ: Lawrence Erlbaum. 